\title{
Relato da experiência de desenvolvimento de um manual de boas práticas em ambientes acadêmicos
}

\author{
Bruna Mariana F. de Souza, Kalil Ferreira, Adrya Araújo, Jeovana Leão, \\ Julis Figueira de Araújo, Mariana Barros, Tanara Lauschner, \\ Fabíola Guerra Nakamura \\ ${ }^{1}$ Universidade Federal do Amazonas (UFAM) \\ 69077-000 - Manaus-AM, Brasil \\ \{bruna.mariana, keff, aadoa, tanara, fabiola\}eicomp.ufam.edu.br \\ \{jeovanaleao, araujojules7, marianafranco\}esuper.ufam.edu.br
}

\begin{abstract}
This article aims to expose the perception of a group of students, under the coordination of a teacher, about their participation in the elaboration of a manual of good practices in the university environment in relation to gender inequality. In addition to presenting the process carried out to date, the article describes the group's expectations about this document, presents the preparation and construction of the material, as well as the group's experience in this creation process. The manual is under development, but its structure and content are already defined, with some sections under review and other sections in writing.
\end{abstract}

Resumo. Este artigo tem como objetivo expor a percepção de um grupo de discentes, sob a coordenação de uma docente, sobre sua participação no desenvolvimento de um manual de boas práticas no ambiente universitário em relação a desigualdade de gênero. Além de apresentar o processo realizado até o momento, o artigo descreve as expectativas do grupo acerca deste documento, apresenta a preparação e construção do material, assim como a experiência do grupo nesse processo de criação. O manual encontra-se em fase de desenvolvimento, porém já está com sua estrutura e conteúdos definidos, com algumas seções em fases de revisão e outras de escrita.

\section{Introdução}

A experiência em uma instituição de ensino superior é algo diferente para cada indivíduo. Contudo, existem algumas situações que acabam sendo comuns a pessoas de certos grupos, como é o caso de discentes mulheres. A passagem delas em uma universidade é diferente comparada a de homens devido a forma como são tratadas por colegas e às vezes por docentes, além das situações em que elas acabam sendo, na maioria dos casos, os alvos mais comuns. Como exemplo são as ocorrências de assédio sexual e moral que acontecem de modo explícito, e também as situações em que uma mulher é desqualificada por causa de seu gênero, que pode ocorrer inclusive de forma velada.

A desigualdade de gênero é segundo Arruda (2018), o contexto que ocorre nas relações sociais e íntimas entre homens e mulheres que, caracterizado num contexto histórico dessas ligações, denotam uma forte subordinação do sujeito social mulher em 
relação ao homem. Essa desigualdade tem retrocedido em muitos pontos - como é o caso da presença feminina que vem crescendo aos poucos em alguns cursos em STEAM (Science, Technology, Engineering, Arts, and Math) que são compostos majoritariamente por homens. Contudo ela cotinua presente em situações, talvez, mais naturalizadas e por isso muitas vezes pode passar despercebida [Ribeiro and Ferreira 2016]. Como no caso da divisão sexual, caracterizada por Pereira e Assis (2017) como “(...) a designação dos homens à esfera produtiva e das mulheres à esfera reprodutiva e, simultaneamente, a apropriação pelos homens das funções com maior valor social".

São situações que muitas vezes podem não ser notadas até para a pessoa que pratica, pois como dizem Souza e Guedes (2016) “(...) é fruto da divisão social estabelecida nas relações sociais entre os sexos", é algo enraizado que promove uma relação desigual entre os sexos e que não é tão discutido nem muito conceituado. Ao tratar sobre prevenção de desigualdade de gênero, violência sexual, dentre outras formas de violências que podem ocorrer em um ambiente universitário, Riddle et. al. (2019) consideram que ações como aumentar a conscientização e reconhecer as barreiras para mudança, devem ser tomadas, de maneira adaptada, para se tratar essas problemáticas, porém entende-se que essas ações ocorrem de maneira lenta.

Este artigo aborda sobre a experiência de alunos no processo da criação de um manual de boas práticas de convivência para estudantes de universidades, que possui foco na desigualdade de gênero. Um estudo feito pelo Instituto Avon/Data Popular (2015) , onde foram entrevistadas 1823 pessoas, das quais $60 \%$ desse público eram mulheres, demonstra que $10 \%$ das mulheres quando perguntadas, dizem ter sofrido de violência por parte de um homem em um ambiente acadêmico, porém quando lhes são demonstradas situações, de uma série de violências possíveis, o número aumenta significativamente para $67 \%$, demonstrando que frequentemente, estudantes passam por situações que são classificadas como algum tipo de violência porém não as consideram, muitas vezes por falta de orientação e conscientização.

Ao procurar formas de como agir em situações de assédio, discriminação, dentre outras, deparam-se com certa dificuldade para conseguir informações simples, como os contatos dentro da universidade que possam prestar auxílio. Segundo o Jornal Nexo (2016) isso ocorre devido ao fato de que muitas vezes as mulheres são desencorajadas a denunciar. Observando-se a realidade em um ambiente universitário, e também notandose a ausência de documentos para auxílio na conscientização dos estudantes, optou-se pela criação de um manual de boas práticas.

O artigo está dividido em quatro seções. A Seção 2 aborda o conteúdo presente no manual. Na Seção 3, relata-se a experiência durante todo o processo de pesquisa e idealização do manual. Na Seção 4, encontram-se as considerações finais.

\section{O manual}

\subsection{Pesquisa e projeto do manual}

O manual idealizado propõe uma série de definições, relatos e informações cujo foco é auxiliar as estudantes universitárias, caso sofram ou presenciem alguma situação na qual não se sintam confortáveis saibam o que está acontecendo, como podem agir e a quem procurar para pedir auxílio caso achem necessário. Para os estudantes do sexo masculino, 
servirá como fonte de informação e sugestões de boa convivência para que o ambiente universitário se torne um local agradável de forma geral.

Durante o processo de levantamento de dados observou-se que a ideia de criação de um material contendo boas práticas de convivência foi colocada em prática em algumas universidades, órgãos governamentais e também em instituições privadas. Ao planejar o nosso próprio manual optou-se por utilizar as melhores práticas já feitas, por trabalhos já existentes e disponibilizados de forma gratuita em sites. Houve o processo de pesquisa de artigos acadêmicos, no qual procuramos as melhores metodologias de desenvolvimento sobre os conceitos a serem abordados na cartilha. Alguns dos manuais pesquisados são citados na seção três do artigo.

\subsection{Desenvolvimento do manual}

Quando se concluiu o que estaria presente no manual começou-se as pesquisas do conteúdo, a princípio demos foco nas definições que ilustrassem determinadas situações e para exemplificá-las, na cartilha, foi decidido criar um formulário para fazer um levantamento de relatos dentro da comunidade acadêmica. Essa consulta com as discentes foi a respeito de situações de assédio sexual e moral, desigualdade de gênero, importunação sexual e discriminação de gênero. Durante essa coleta de relatos foram realizadas pesquisas em sites e artigos para a elaboração do conteúdo.

Os tópicos foram pensados levando em conta a pesquisa realizada e a realidade da universidade. Foi decido conceituar algumas principais questões que fazem parte da realidade de algumas mulheres, como o assédio moral, sexual e como reagir nesses casos, discriminação contra a mulher, divisão sexual e a desiguldade de gênero. Outros itens foram definidos visando instruir discentes a respeito da desigualdade de gênero no ambiente universitário, quais os desafios e dificuldades dela dentro da universidade, porque se preocupar com ela, situações de exemplo e ações para mudanças. Além disso, criouse um tópico para explicitar os contatos, dentro do instituto de ensino, responsáveis por denúncias e/ou assistência estudantil. Na Figura 1 é apresentado o fluxograma das etapas para o desenvolvimento do manual.

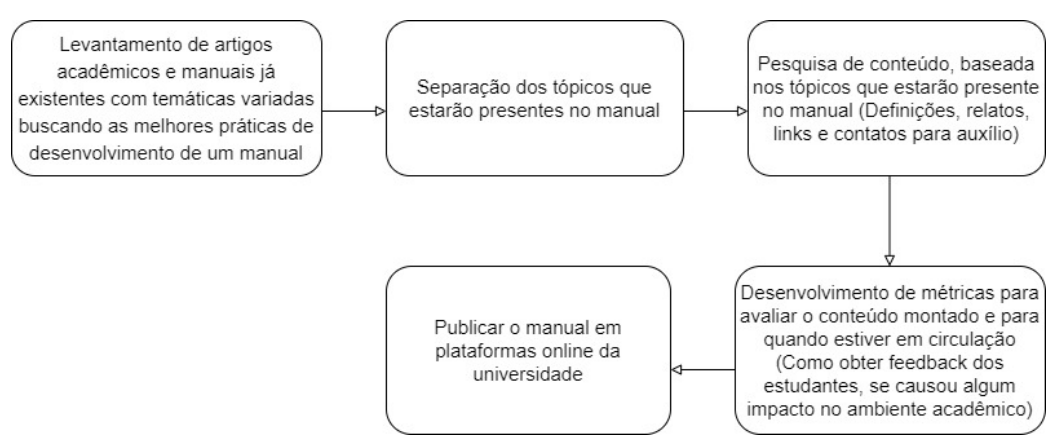

Figura 1. Fluxograma das etapas para o desenvolvimento do manual.

\section{Relato da experiência}

O grupo de discentes que fez parte da idealização da cartilha de boas práticas não possuía experiência em um trabalho como esse e, por isso, enfrentou dificuldades em saber o que seria relevante para o manual. Desta forma, ao realizar o levantamento do conteúdo que 
estaria presente, percebeu-se a necessidade de adotar métricas de avaliação primeiramente para a etapa de desenvolvimento. Com esse pensamento, decidiu-se entrar em contato com pessoas que já desenvolveram manuais, preferencialmente, em outras universidades do Brasil para obter sugestões de como proceder e também para conhecer as experiências deles.

Foi mandado e-mail para algumas instituições de ensino e organizações privadas que possuíam manuais e contatou-se as pessoas que os desenvolveram com uma série de perguntas relacionadas a eles. Com as respostas recebidas percebeu-se que não existe uma forma padrão de coleta de dados para medir adesão e o quão importante o material foi para a comunidade acadêmica. Alguns pontos levantados pelas pessoas responsáveis referemse à resposta pública e ao aumento da procura por assistência como fatores de avaliação. A respostas foram bem variadas no que se refere a motivação, mas era similiares no sentido de tentar compreender e melhorar o ambiente no qual a cartilha se aplicava, o que se alinha com a motivação dos desenvolvedores deste artigo.

A idealização deste manual de boas práticas por parte do grupo de estudantes deu-se com a percepção de que boa parte do corpo discente dos cursos de STEAM do ensino superior não tem conhecimento sobre situações de desigualdade e discriminações de gênero que muitas vezes ocorrem no dia a dia. Avaliá-lo e determinar quais são as melhores práticas ao se criar uma cartilha de boa convivência provou-se trabalhoso e longo, devido à variedade de tópicos que poderiam auxiliar no tema. Apesar de ser uma ideia colocada em prática por instituições públicas e privadas, existe a falta de conteúdo de apoio com relação a artigos sobre formas de desenvolvimento e até mesmo de avaliação de impacto causados por manuais. No que se refere a conteúdo em outras línguas, é possível encontrar-se alguns, porém continua sendo consideravelmente pouco.

Não foram encontrados artigos que relataram sobre a experiência de pessoas por trás da criação de um manual de convivência, contudo, foram encontrados trabalhos que produziram ideias semelhantes do material referido neste artigo alguns distinguindo-se no público-alvo e outros em seus temas. Todos tiveram o mesmo propósito, indicar ações para a melhoria das práticas de boa convivência, a maioria com relação às mulheres, dentro de um ambiente seja acadêmico ou profissional. Dois dos trabalhos encontrados, semelhantes ao idealizado pelo grupo, foram: "Cartilha Violência de Gênero na Universidade aborda a violência contra a mulher" [CAV Mulheres 2018] cujo tema é a violência contra a mulher e "Cartilha de boas práticas por mulheres de T.I. em Recife" [Mulheres de T.I. em Recife 2018] com o objetivo de apontar algumas ações para mudar o cenário das dificuldades de mulheres que trabalham na área de TI em Recife.

Com o propósito de ser escrito em vocabulário simples, com ilustrações e pouco texto, a expectativa da equipe é que o material tenha uma boa receptividade na comunidade acadêmica e que sirva de guia em como proceder em certas situações, especialmente envolvendo discriminação, assédio ou casos de desigualdade de gênero.

\section{Considerações finais}

Durante a pesquisa e a avaliação do que ia ser colocado no manual foi possível aprender muitos conceitos e informações importantes que antes o grupo responsável não tinha conhecimento ou sabia pouco. Com isso, as próprias pessoas que fizeram parte do desenvolvimento do manual puderam conhecer mais sobre as situações em que uma mulher 
pode ser alvo, ações para mudanças e outros temas em torno da desigualdade de gênero, e ainda conhecer a realidade de outras instituições.

Todo esse conhecimento foi muito importante para as pessoas que participaram e aumento o desejo delas de que outras pessoas conhecessem mais sobre o tema. O manual ainda está sendo desenvolvido, mas espera-se que ele possa mudar a percepção de muitas pessoas sobre a desigualdade de gênero e ainda que possa levantar boas questões a serem discutidas dentro da universidade, fazendo com que o ambiente acadêmico seja um local mais acolhedor, seguro e bem receptivo para todas as mulheres.

\section{Agradecimentos}

Esta pesquisa, realizada no âmbito do Projeto Samsung-UFAM de Ensino e Pesquisa (SUPER), nos termos do artigo 48 do Decreto $n^{\circ}$ 6.008/2006 (SUFRAMA), foi parcialmente financiada pela Samsung Eletrônica da Amazônia Ltda., nos termos da Lei Federal $\mathrm{n}^{\mathrm{o}}$ 8.387/1991, por meio dos convênios 001/2020 e 003/2019, firmados com a Universidade Federal do Amazonas e a FAEPI, Brasil.

\section{Referências}

Arruda, P. A. (2018). A desigualdade de gênero caracterizada pelo violência contra a mulher. Revista Saberes Docentes, 3(6).

CAV Mulheres (2018). Relatório Final de Atividades Gestão 2016-2018. Disponível em https://edisciplinas.usp.br/pluginfile.php/5485034/

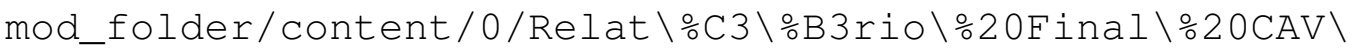
$\circ 20 \mathrm{Mulheres.pdf}$, Acesso em Fevereiro de 2021.

Instituto Avon/Data Popular (2015). Violência contra a mulher no ambiente universitário. Disponível em https: / / avongroup.vteximg.com.br/arquivos / violencia-contra-a-mulher-no-ambiente-universitario.pdf. Acesso em Fevereiro de 2021.

Jornal Nexo (2016). Como as maiores universidades do mundo combatem o assédio sexual no campus. Disponível em https: //www.nexojornal.com.br/expresso/2016/07/28/ Como-as-maioresuniversidadesdo-mundo-combatem-o-ass $\$ C3 \%A9dio-sexual-no-campus. Acesso em Fevereiro de 2021.

Mulheres de T.I. em Recife (2018). Cartilha de boas práticas por mulheres de t.i. em recife. Disponível em: https://www.mulheresdeti.recife.br/. Acesso em Fevereiro de 2021.

Pereira, I. T. and Assis, L. M. (2017). Mulher e trabalho: divisão sexual do trabalho. In $X$ JIDEEP-Jornadas de Investigación, Docencia, Extensión y Ejercicio Profesional (La Plata, 2017).

Ribeiro, V. C. M. and Ferreira, M. d. L. A. (2016). Desigualdade de gênero na universidade: ênfase no sexo feminino. Revista Desenvolvimento Social, 18(1):53-64.

Ridde, V., Dagenais, C., and Daigneault, I. (2019). It's time to address sexual violence in academic global health.

Sousa, L. P. d. and Guedes, D. R. (2016). A desigual divisão sexual do trabalho: um olhar sobre a última década. Estudos avançados, 30(87):123-139. 